\title{
Prevalence, withdrawal symptoms and associated factors of khat chewing among students at Jimma University in Ethiopia
}

\author{
Tilahun Abdeta ${ }^{1 *}$, Daniel Tolessa ${ }^{2}$, Kristina Adorjan $^{3,4,5}$ and Mubarek Abera ${ }^{6}$
}

\begin{abstract}
Background: Recently, khat chewing has become a common practice among high school, college, and university students. Regular khat chewing is thought to be a predisposing factor for different physical and mental health problems. It can lead to absenteeism from work and classes. In Ethiopia, to our knowledge no published study has investigated khat withdrawal symptoms. Therefore, this study was conducted to determine the prevalence, withdrawal symptoms, and associated factors of khat chewing among regular undergraduate students on the main campus of Jimma University in Ethiopia.

Methods: The institution-based, cross-sectional study was conducted in January 2016. Data were collected from 651 main campus regular undergraduate students with a structured, self-administered questionnaire, entered into Epidata 3.1 and exported to SPSS version 20 for Windows. Bivariate and multivariate logistic regressions were used to explore associations and identify variables independently associated with khat chewing.

Results: The study found that the lifetime and current prevalence of khat chewing among students were $26.3 \%$ (95\% Cl: $24.3,28.3)$ and $23.9 \%$ (95\% Cl: 21.94, 25.86), respectively. About $25.7 \%$ of students started chewing after joining university, and $60.5 \%$ of these students started during their first year. The main reason given for starting khat chewing was for study purposes (54.6\%), followed by socialization purposes (42.3\%). Among current khat chewers, 72.9\% reported that they had chewed khat for 1 year or more and 68.2\% reported that they had experienced various withdrawal symptoms. The most frequently reported withdrawal symptoms were feeling depressed, craving, and feeling fatigued. Being male, attending a place of worship daily/2-3 times per week, cannabis use, smoking cigarettes, and having family members currently chewing khat were independently associated with khat chewing.

Conclusions: This study found that large numbers of university students were currently chewing khat. In this study withdrawal symptoms and factors that significantly affect khat chewing were identified. Besides it gave new ideas regarding khat withdrawal symptoms in Ethiopia. It serves as a critical role of providing information to form rational foundation for public health policy, prevention and planning to bring change in contributing factors for Khat chewing. The finding will be serving as base line information for further study.
\end{abstract}

Keywords: Prevalence, Khat use, Withdrawal symptoms, Student, Jimma University

\footnotetext{
*Correspondence: tilahunabdeta@gmail.com

'Department of Psychiatry, School of Nursing and Midwifery, College of

Medical and Health Sciences, Haramaya University, Harar, Ethiopia

Full list of author information is available at the end of the article
} 


\section{Background}

Substance abuse, including khat chewing, is as old as the history of mankind. Khat (Catha edulis) is a large green shrub that grows at high altitudes (between 1500 and $2000 \mathrm{~m}$ above sea level) in the region extending from eastern to southern Africa and in the Arabian Peninsula $[1,2]$. The plant is known by different names in different countries: "chat" in Ethiopia, "qat" in Yemen, "mirra" in Kenya, and "qaadorjaad" in Somalia; however, "khat" is the name commonly used in the literature [3].

The origin of khat is not clear, but it is generally agreed that khat is native to Ethiopia (Hararghe zone) and was first used there [4]. Fresh khat leaves contain more than 40 chemicals that vary depending on where it was grown, type variation, etc [5]. However, most of the stimulant effect of khat is thought to come from the chemicals cathinone, cathine, and norephedrine, all of which stimulate the central nervous system in a similar way to amphetamine. Cathinone has been reported to be $7-10$ times more potent than cathine $[6,7]$. Cathinone plasma levels peak 1.5-3.5 h after khat chewing [8].

Recently, khat chewing has become a common practice among high school, college, and university students for recreational purposes and because they believe that it increases their academic performance [9, 10]. The World Health Organization (WHO) has classified khat as a drug of abuse that can produce mild to moderate psychological dependence [11-14]. According to the WHO, chronic khat use can result in a variety of physical illnesses, including urinary retention, impotence, oral cancer, dental caries, chronic gastritis, hemorrhoids, paralytic ileus, liver cirrhosis, hypertension, and blurred vision. Besides, it can cause psychotic and suicidal depressive reactions, mania and have effects on the central nervous system, e.g. dizziness, impaired cognitive functioning, fine tremor, insomnia, and headaches. Khat chewers have a significantly higher mortality rate due to chronic illnesses such as heart disease and stroke than non-khat chewers, and khat chewing among youths can increase the risk of contracting human immunodeficiency virus (HIV) and other sexually transmitted diseases [15-22].

Khat chewers spend long hours chewing and then recovering from chewing, which can lead to a loss of work hours and absenteeism from work and classes and potentially result in a decrease in overall national economic productivity and poor academic performance among students [23-26].

The available literature is inconsistent regarding the presence or absence of khat withdrawal symptoms. One study on the pharmacological and medical aspects of khat and its social use in Yemen found that when chronic khat chewers stop chewing, they develop withdrawal symptoms such as feeling hot in their legs, nightmares, mild depression, slight tremor, lethargy, a desire to chew khat, and so on [27]. However, another study on substance abuse in outpatients attending rural and urban health centers in Kenya found no signs of khat dependency or withdrawal symptoms [28]. No research is available on the prevalence, withdrawal symptoms, and associated factors of khat chewing in our study area, and we found no study on khat withdrawal symptoms in other regions of Ethiopia. Therefore, the objective of this study was to determine the prevalence, withdrawal symptoms, and associated factors of khat chewing among regular undergraduate students of the main campus at Jimma University, Ethiopia, to provide additional information on the prevalence of khat chewing and khat withdrawal symptoms.

\section{Methods}

\section{Study area and period}

This study was conducted in January 2016 among 651 regular undergraduate students of the main campus at Jimma University, Ethiopia. Jimma University is located in Oromia regional state, $352 \mathrm{~km}$ from Addis Ababa, in the southwest of the country and is one of the public higher education institutions in Ethiopia. The university currently has four campuses: (I) Main Campus; (II) College of Agriculture and Veterinary Medicine; (III) Kitofurdisa campus (Institute of Technology/IOT); and (IV) Business and Economics College. Our study was conducted at the Main Campus, which has three colleges (College of Health Sciences, College of Natural Science, and College of Social Science and Law). The reason why we chose main campus is; it has relatively many students of different colleges and many departments under each college. But the rest campuses have very specific colleges which could affect our results especially the prevalence of chewing khat. The main campus has a total of 6304 regular undergraduate students, 4599 of whom are male and 1705 female.

\section{Study design}

Institution based cross-sectional study design was facilitated.

\section{Source population}

All regular undergraduate students registered for the 2016 academic year in main campus, Jimma University were considered as source population.

\section{Study population}

All selected regular undergraduate students registered for 2016 academic year in main campus, Jimma University were considered as a study population.

\section{Inclusion criteria}

All regular undergraduate students registered from 1st to 6th year and attending their education during the 
study period in main campus, Jimma University were included in the study.

\section{Sample size determination}

From the results of a previous study done on the subject matter among Ethiopian university students we took population proportion $27.9 \%$ [29]. Using the formula for the sample size of single population proportion:

$$
\mathrm{ni}=\frac{(z a / 2)^{2} p(1-p)}{\mathrm{d}^{2}}
$$

Where

$\mathrm{ni}=$ initial sample size

$a=$ confidence interval (95\%)

$\mathrm{p}=$ proportion of Khat chewing: $27.9 \%$,

$\mathrm{d}=$ is the margin of sampling error tolerated (5\%)

$$
\mathrm{ni}=\frac{(1.92)^{2} .0 .279(1-0.279)}{(0.05) 2}=\frac{3.8416 \times 0.279 \times 0.721}{0.0025}=310
$$

Since the total number of regular students in the main campus is 6304 which is less than 10,000, Using finite population correction formula the final sample size was;

$$
\mathrm{n}_{\mathrm{f}}=\frac{n i}{1+(n i / N)}
$$

where,

$\mathrm{nf}=$ final sample size

ni = initial sample size calculated above (310)

$\mathrm{N}=$ total number of undergraduate regular students.

$$
\mathrm{n}_{\mathrm{f}}=\frac{310}{1+(310 / 6304)}=296
$$

Since we had employed a multistage sampling technique we multiplied the sample size by two in order to correct bias that was introduced in the sampling design. Therefore, the final sample size became $296 \times 2=592$. Again this is a self-administered study as a result we considered a $10 \%$ non-response rate. So, by adding $10 \%$ non-response rate, the final sample size was 651 .

\section{Sampling procedure}

The study was conducted using a multistage sampling technique. First stage was formed using colleges and two out of three colleges were selected to increase the representativeness through lottery method. In the second stage again 10 departments in the selected colleges were proportionally allocated. Sample size for each department and year of study was allocated according to proportion to the number of students in the specific department and year of study by using the following proportional allocation formula, and each respondent was selected by a simple random sampling technique (see Fig. 1).

Proportional allocation formula: $\mathrm{n}_{\mathrm{x}}=\frac{n \cdot N x}{N T}$.
Where:

$\mathrm{nx}=$ sample from department $\mathrm{x}$

$\mathrm{Nx}=$ total number of student in department $\mathrm{x}$

$\mathrm{NT}=$ total number of students in the selected collages and

$\mathrm{n}=$ total sample size

\section{Study variables}

Dependent variables

History of current khat chewing

\section{Independent variables}

$>$ Socio-demographic factors

Age, Sex, Marital status, Ethnicity, Religion, Frequency

of attending a place of worship, Monthly pocket

money, Residence before, Current and previous Living

condition, Family's main source of income, Families

chewing habit.

$>$ Substance use other than khat use

Alcohol use, Cigarette smoking, Cannabis use, Shisha and other substances use.

$\gg$ School related factors

Cumulative grade point, colleges, Year of study.

\section{Data collection procedures}

A self-administered, structured questionnaire adapted from the literature was used. The questionnaire had three parts: (I) socio-demographic information; (II) khat chewing habits and substance use other than khat; and (III) checklist to assess khat withdrawal symptoms. The questionnaire was translated into both Amharic and Afan Oromo, languages that most students could understand. Both versions were then back-translated into English by an independent translator. Finally, the questionnaire was administered in both Amharic and Afan Oromo. Six supervisors (three clinical nurses $[\mathrm{BSc}]$ and three psychiatric nurses $[\mathrm{BSc}]$ ) and the principal investigator closely supervised the overall data collection. Data collectors were nine psychiatric nurses (four MSc and five $\mathrm{BSc}$ ), and one BSc clinical nurse.

\section{Data quality management}

The questionnaire was pre-tested by data collectors on 33 students from the campus of College of Agriculture and Veterinary Medicine 1 week before the start of data collection for the main study. Data collectors and Supervisors were given 1 day of training. Collected data were checked for completeness, coded, entered into Epidata 3.1 and then exported to SPSS version 20 for Windows for statistical analysis. 


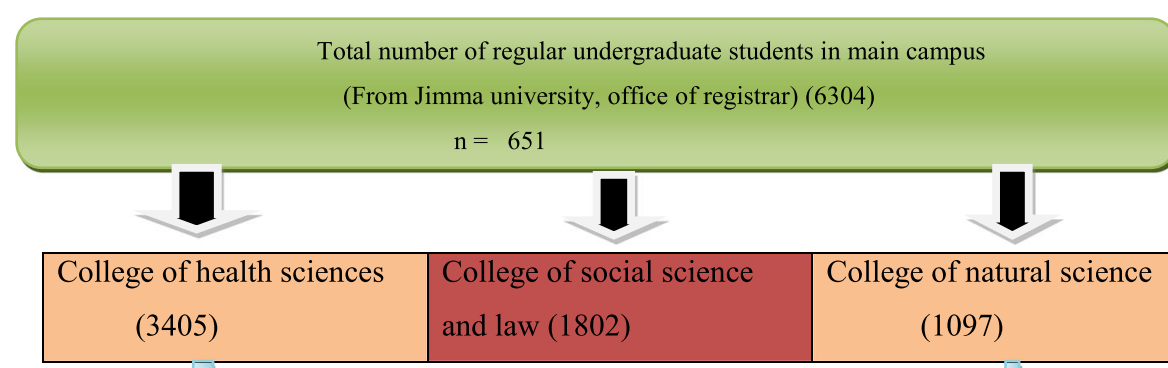

(First stage: 2 colleges were selected by lottery method)

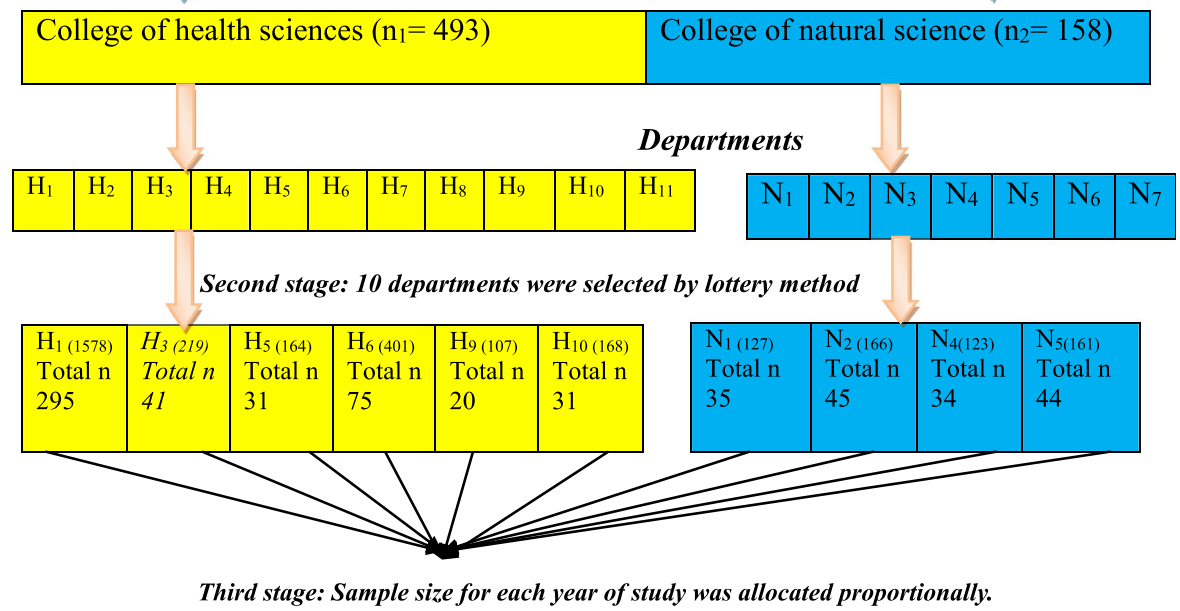

Fig. 1 The schematic presentation of the sampling procedure employed among undergraduate students, Jimma University, Ethiopia, 2016

\section{Data processing, analysis and interpretation}

After all necessary data obtained, data were checked manually for completeness and questionnaires with incomplete data were excluded. Data were edited, coded and entered in to Epidata version3.1 then exported and analyzed by SPSS version 20 for windows. Descriptive statistics such as measures of central tendency, standard deviations, and frequencies including cross tabulation were used to summarize data. Bivariate and multivariate logistic regressions were used to explore the presence of associations and identify independent predictors of khat chewing. Variables with a $p$-value $<0.25$ in the bivariate analysis were entered into multivariate logistic regressions in order to control for potential confounders and calculate adjusted odds ratios with a 95\% confidence interval $(95 \% \mathrm{CI})$. Variables with $p<0.05$ in the multivariate logistic regressions were considered as significantly associated with khat chewing.

\section{Ethical consideration}

The study was approved by the ethical review board of the College of Health Sciences, Jimma University. Immediately before the questionnaire was distributed, written informed consent was obtained from the study participants after they had been given a clear explanation of the study objectives. The collected data were kept confidential. The participants were informed about their right to refuse to participate and to ask anything about the study. The names of the study participants were not written in order to keep their privacy. Beside the study was conducted using self administered questionnaire which ensures participants' privacy and encourages them to give their ideas freely. Since the study was conducted by self administered questionnaire and due to privacy issue we could not find individuals with problem (khat chewing). However since the prevalence of current khat chewing in this study was relatively high; we had given mass-education for all under graduate students of main campus with suggesting the availability of help/treatment at psychiatry clinic of Jimma University specialized hospital and Students with the problem can be evaluated and get appropriate treatment in the hospital.

\section{Operational definitions}

Lifetime prevalence of khat chewing: Defined as the proportion of students who had ever used khat at least once in their lifetime [30].

Current prevalence of khat chewing: Defined as the proportion of students who used khat at least once during the last 1 month preceding the study [31]. 
Khat withdrawal symptoms: The usually unpleasant set of physical or psychological symptoms experienced due to the cessation of (or reduction in) khat use during the last 1 month preceding the study [32].

Craving: Feeling desire to chew khat again and again [32].

\section{Results}

Socio-demographic characteristics of respondents

Of 651 students provided with self-administered questionnaires, 619 completed and returned them (response rate: $95.1 \%) ; 75.0 \%$ of the respondents were males and $25.0 \%$ females. The mean (SD) age of participants was 21.89 (2.30) years and the majority (97.1\%) were single. Large proportions $(39.7 \%)$ of the respondents were Orthodox Christians, followed by Muslims (29.6\%). The majority of respondents (62.2\%) were of Oromo ethnicity, followed by Amhara (20.5\%). Most respondents (61.7\%) were originally from an urban area, had previously been living with their family $(94.0 \%)$ and were currently living in a dormitory (93.5\%). The main source of income of the respondents' families was agriculture (40.7\%), followed by employment in governmental institutions (29.1\%). Large proportion of the students (91.1\%) received some monthly pocket money. The $77.9 \%$ of the students were from Health Sciences College, and students in the first year of study of their respective department accounted for the largest proportion (24.6\%), followed by third-year students (23.9\%). Apart from the first-year students (24.6\%), all students (75.4\%) reported their cumulative Grade Point Average (cGPA); large proportion of them $(51 \%)$ had a cGPA $<3.25$ (see Table 1 ).

\section{Khat chewing practice}

The lifetime and current prevalence of khat chewing among students were (26.3\%; 95\% CI: $24.3,28.3)$ and (23.9\%; 95\% CI: 21.94, 25.86), respectively. The majority of current khat chewers (66.9\%) reported that they started khat chewing after the age of 15 years. The mean (SD) age for starting khat chewing was 17.2 (3.2).

Among the current khat chewers, $36.5 \%$ chewed khat 2-3 times a week, $35.1 \%$ daily, $25.7 \%$ weekly, and $2.7 \%$ occasionally. Majority of them (54.1\%) spent $>25$ Ethiopian Birr (ETB) on khat for each session, and the others 16-25 ETB (27.7\%) and $\leq 15$ ETB (18.2\%). The mean duration of a khat chewing session was $2-4 \mathrm{~h}$ for $41.2 \%$ of the current khat chewers, $<2 \mathrm{~h}$ for $29.7 \%$ and $>4 \mathrm{~h}$ for $29.1 \%$.

Reasons reported by respondents for starting khat chewing A total of $74.3 \%$ of current chewers started chewing khat before joining university. The remainder (25.7\%) started chewing after joining university, mostly in their first year $(60.5 \%)$. The main reason given for starting khat chewing was for study purposes (54.6\%), followed by socialization purposes (42.3\%) (See Fig. 2).
Table 1 Socio-demographic characteristics of undergraduate students at Jimma University, Ethiopia, 2016

\begin{tabular}{lll}
\hline Socio-demographic characteristics & Frequency $(\mathrm{n})$ & Percent (\%) \\
\hline Sex $(n=619)$ & & 75.0 \\
$\quad$ Male & 464 & 25.0 \\
$\quad$ Female & 155 & \\
Age $(n=619)$ & & 32.3 \\
$<20$ & 200 & 52.7 \\
$20-24$ & 326 & 15.0 \\
25 and above & 93 & \\
Marital status $(n=619)$ & & 97.1 \\
Single & 601 & 2.9 \\
$\quad$ Married & 18 & \\
Religion ( $n=619)$ & & 39.7 \\
Orthodox Christian & 246 & 29.6 \\
Muslim & 183 & 25.4 \\
Protestant & 157 & 5.4 \\
Other &
\end{tabular}

Frequency of attending a place of worship $(n=619)$

\begin{tabular}{|c|c|c|}
\hline Daily & 257 & 41.5 \\
\hline 2-3 times per week & 188 & 30.4 \\
\hline Weekly & 94 & 15.2 \\
\hline Less than weekly & 37 & 6.0 \\
\hline Never & 43 & 6.95 \\
\hline \multicolumn{3}{|l|}{ thnicity $(n=619)$} \\
\hline Oromo & 385 & 62.2 \\
\hline Amhara & 127 & 20.5 \\
\hline Guraghe & 22 & 3.6 \\
\hline Tigre & 13 & 2.1 \\
\hline Wolayita & 23 & 3.7 \\
\hline Other ${ }^{b}$ & 49 & 7. \\
\hline
\end{tabular}

Area of residence before joining university $(n=619)$

$\begin{array}{lll}\text { Urban } & 382 & 61.7\end{array}$

$\begin{array}{lll}\text { Rural } & 237 & 38.3\end{array}$

Living situation before joining university $(n=619)$

Living alone $\quad 29 \quad 4.7$

Living with family $\quad 582 \quad 94.0$

Other $^{c}$

8

1.3

Current living situation $(n=619)$

Dormitory 579

Rented accommodation $\quad 28 \quad 4.5$

Other $^{\mathrm{d}} \quad 12 \quad 2$

Family's main source of income $(n=619)$

Agriculture $\quad 252 \quad 40.7$

Government job $\quad 180 \quad 29.1$

$\begin{array}{lll}\text { Trade } & 142 & 22.9\end{array}$ 
Table 1 Socio-demographic characteristics of undergraduate students at Jimma University, Ethiopia, 2016 (Continued)

\begin{tabular}{lll}
\hline NGO/private firm work & 32 & 5.2 \\
Other $^{\mathrm{e}}$ & 13 & 2.1
\end{tabular}

Average monthly pocket money (Ethiopian birr) $(n=564)$

$\begin{array}{lll}1-100 & 26 & 4.2 \\ 101-299 & 96 & 15.5 \\ 300-499 & 165 & 26.7 \\ 500-999 & 188 & 30.4 \\ 1000 \text { and above } & 89 & 14.4\end{array}$

College

College of Health Sciences $\quad 482 \quad 77.9$

College of Natural Sciences $\quad 137 \quad 22.1$

Year of study $(n=619)$

First year 152

$\begin{array}{lll}\text { Second year } & 141 & 22.8\end{array}$

$\begin{array}{lll}\text { Third year } & 148 & 23.9\end{array}$

Fourth year and above $\quad 178 \quad 28.7$

Cumulative grade point average (CGPA) $(n=467)$

$<3.25$ / less than distinction level $\quad 238 \quad 51$

$\geq 3.25$ / distinction level

229

${ }^{a}$ Catholic, Hawariyat, or traditional

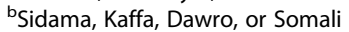

'Living with relatives or in own home with husband or wife

${ }^{\mathrm{d}}$ Living with relatives or family

eOwn business

\section{Khat withdrawal symptoms}

Among current khat chewers, 72.9\% reported that they had chewed khat for 1 year or more and the majority (68.2\%) of them reported experiencing different withdrawal symptoms when they stopped chewing khat or reduced the amount of khat they chewed. The most frequently reported withdrawal symptoms were feeling depressed (65.3\%), craving (44.6\%), feeling fatigued (36.6\%), increased appetite (29.7\%), irritability (26.7\%), hypersomnia (20.8\%) and nightmares (20.8\%). Besides these symptoms, insomnia (13.8\%), feeling hot all over (10.9\%), feeling hot in arms (5.9\%), slight tremor of the tongue (4.95\%), slight tremor of the hand (3.94\%), feeling hot in legs $(2.97 \%)$, slight tremor of the whole body $(1.9 \%)$ and headache $(0.9 \%)$ were also reported. (See Fig. 3). Among those who reported withdrawal symptoms, $55.4 \%$ usually felt the symptoms for more than ten hours, $7.9 \%$ for $6-10 \mathrm{~h}, 23.8 \%$ for $1-5 \mathrm{~h}$, and $12.9 \%$ for $<1 \mathrm{~h}$. Also, a large proportion of them (66.3\%) reported that the withdrawal symptoms cause impairment in social, occupational, or other important areas of their functioning. The majority of those who reported having withdrawal symptoms (52.5\%) use different measures to get relief: $34 \%$ use coca or coffee, $28.3 \%$ chew khat, $20.75 \%$ sleep, $11.3 \%$ do sport or watch a movie, $3.7 \%$ take a shower and $1.9 \%$ use candy for a long time.

\section{Factors independently associated with current khat chewing}

To determine the association between dependent and independent variables, we performed bivariate and multivariate logistic regression analyses. The multivariate logistic regression analysis found that male students had 2.3 times higher odds of chewing khat than females (AOR2.3, 95\% CI: 1.16, 4.6).

Irrespective of their religion, students who were attending a place of worship daily or 2-3 times per week were $90 \%$ less likely to chew khat than students who never attended a place of worship during the last month (AOR 0.1, 95\% CI: 0.03, 0.29). Students those who have

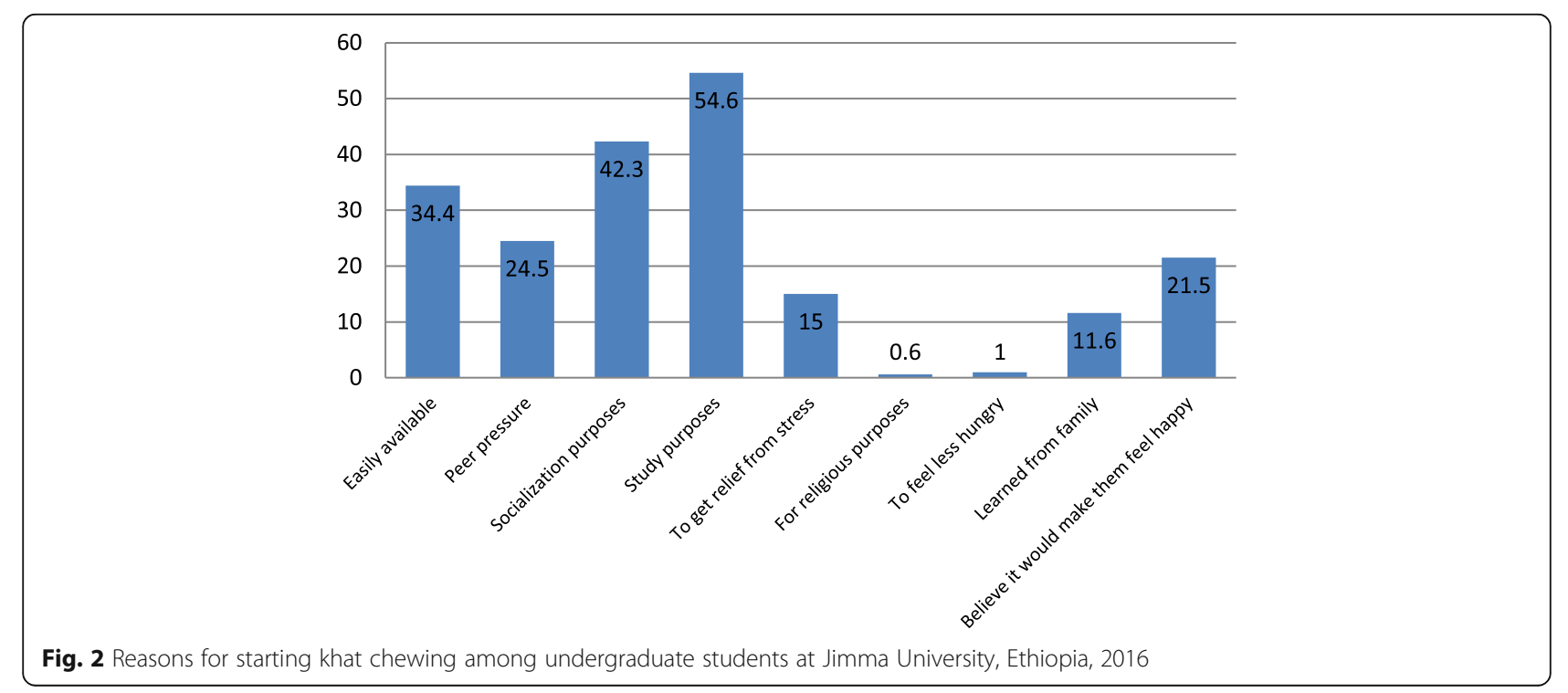




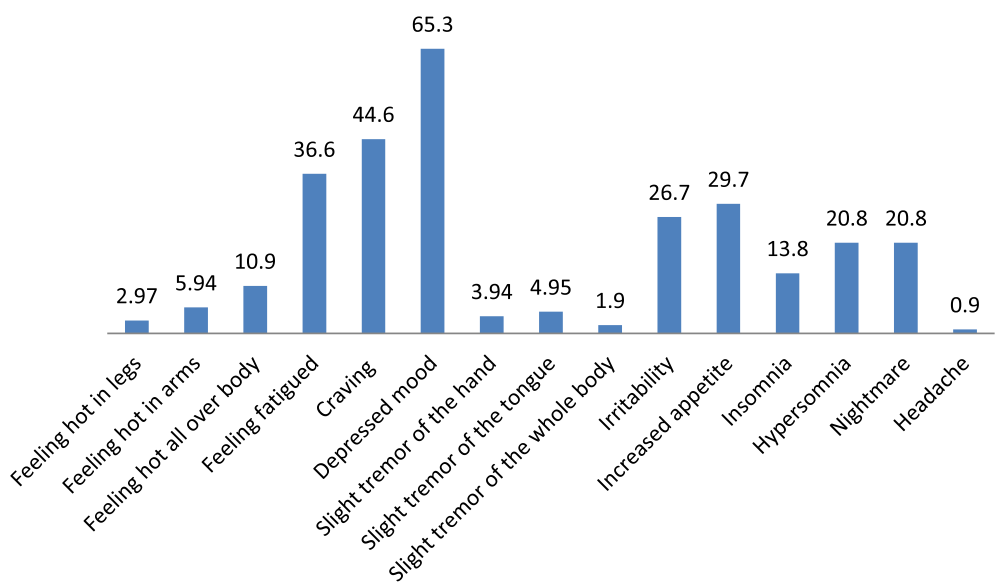

Fig. 3 Withdrawal symptoms reported among undergraduate students at Jimma University, Ethiopia, 2016

family members currently chewing khat had 15.6 times higher odds of chewing khat than those who have no family members currently chewing khat (AOR 15.6, 95\% CI: 8.3, 29.5). Students who had used cannabis at least once during the last month had more than four times higher odds of chewing khat than those who did not use it during the last month (AOR 4.17, 95\% CI: 1.6, 11.2). Students those who had not smoked cigarettes during the last month were 55\% less likely to chew khat than those who had smoked cigarettes at least once during the last month (AOR 0.45, 95\% CI: 0.3, 0.7).

Age, marital status, ethnicity, family's main source of income, and current drinking alcohol were statistically significant in the binary logistic regression analysis but not significant when adjusted for other variables in the final model (See Tables 2 and 3).

\section{Discussion}

This study assessed the prevalence, withdrawal symptoms, and associated factors of khat chewing.

The current prevalence of khat chewing (23.9\%) found in this study is in line with that found among students at Jazan University, Saudi Arabia (23.1\%) [33] And undergraduate students at Haramaya University, Ethiopia (23.6\%) [34]. However, the prevalence is higher than that found at Addis Ababa University and Gondar University and at four other colleges in North West Ethiopia $[10,35,36]$. The possible reasons for the different rates could be differences in the study settings, such as access to khat, and factors outside the university environment, for example in Jimma town chewing khat is more common and is normalized by the community [37]. The prevalence in this study was also lower than that in a study conducted among students at Axum University in April 2012 (27.9\%) [29]; this difference could be due to different sample sizes.
In our study, a large proportion of current khat chewers $(74.3 \%)$ reported that they started chewing khat before joining university. Among those who started after joining university (25.7\%), the majority (60.5\%) started when they were first-year students. This result is supported by previous findings at Gondar University and four other colleges in North West Ethiopia [15, 36]. A possible explanation for the higher rate among first-year students may be a maladaptive response to stressors such as the new environment, academic stress, separation from their family, and the contents of learning. In agreement with these explanations, in this study the main reason given for starting khat chewing was for study purposes $(54.6 \%)$, followed by socialization purposes $(42.3 \%)$. All these statements are important indicators for interventions aimed at decreasing the prevalence of khat chewing among undergraduate students at university.

This study found that $36.5 \%$ of current khat chewers chew khat 2-3 times a week, $54.1 \%$ chew khat costing $>25$ ETB per chewing session, and $29.1 \%$ spend $>4$ h per chewing session. These findings were comparable to those of other studies among university students at Jazan University, Saudi Arabia [33], and college students in Bahir Dar town [38], Ethiopia, and indicate that students spend a lot of money and time on khat chewing. This use of resources may have an impact on social and economic aspects of the students' lives and their health and academic performance. Furthermore, if students have no money to buy khat they could be tempted to engage in criminal activities.

To our knowledge this study is the first in Ethiopia to investigate khat withdrawal symptoms. The findings of the few available studies regarding the presence or absence of khat withdrawal symptoms are inconsistent. The findings of the current study are in line with those of one previous study finding in Yemen, which showed 
Table 2 Socio-demographic factors independently associated with current khat chewing among undergraduate students, Jimma University, Ethiopia, 2016

\begin{tabular}{|c|c|c|c|c|}
\hline \multirow[t]{2}{*}{ Variables } & \multicolumn{2}{|c|}{ Current khat chewing } & \multirow[t]{2}{*}{$P$-value } & \multirow[t]{2}{*}{ AOR $(95 \% \mathrm{Cl})$} \\
\hline & Yes & No & & \\
\hline \multicolumn{5}{|l|}{ Age } \\
\hline$<20$ & $38(19)$ & $162(81)$ & 0.5 & $0.75[0.3-1.8]$ \\
\hline $20-24$ & 78 (23.9) & $248(76.1)$ & Reference & Reference \\
\hline$\geq 25$ & $32(34.4)$ & $61(65.6)$ & 0.49 & $0.76[0.35-1.67]$ \\
\hline \multicolumn{5}{|l|}{ Sex } \\
\hline Male & $125(26.9)$ & $339(73.1)$ & 0.02 & $2.3[1.16-4.6]$ \\
\hline Female & $23(14.8)$ & $132(85.2)$ & Reference & Reference \\
\hline \multicolumn{5}{|l|}{ Marital status } \\
\hline Single & $139(23.1)$ & $462(76.9)$ & Reference & Reference \\
\hline Married & $9(50)$ & $9(50)$ & 0.44 & $0.49[0.08-3.0]$ \\
\hline \multicolumn{5}{|l|}{ Ethnicity } \\
\hline Oromo & $112(29.1)$ & $273(70.9)$ & Reference & Reference \\
\hline Amhara & $15(11.8)$ & $112(88.2)$ & 0.06 & $2.1[0.96-4.5]$ \\
\hline Others $^{\mathrm{a}}$ & $21(19.6)$ & $86(80.4)$ & 0.3 & $0.56[0.18-1.7]$ \\
\hline \multicolumn{5}{|l|}{ Religion } \\
\hline Muslim & $91(49.7)$ & $92(50.3)$ & Reference & Reference \\
\hline Orthodox & $41(16.7)$ & $205(83.3)$ & 0.001 & 6.7 [2.8-16.3] \\
\hline Others ${ }^{b}$ & $16(8.4)$ & 174 (91.6) & 0.001 & 4.0 [1.76-9.37] \\
\hline \multicolumn{5}{|c|}{ Frequency of attending a place of worship } \\
\hline Daily/2-3 times per week & $96(21.6)$ & $349(78.4)$ & 0.001 & $0.1[0.03-0.29]$ \\
\hline Weekly & $28(29.8)$ & $66(70.2)$ & 0.3 & $0.55[0.17-1.7]$ \\
\hline Less than weekly & $7(17.1)$ & $34(82.9)$ & 0.13 & $0.19[0.04-0.84]$ \\
\hline Never & $17(43.6)$ & $22(56.4)$ & Reference & Reference \\
\hline \multicolumn{5}{|l|}{ Previous living condition } \\
\hline Living Alone & $4(13.8)$ & $25(86.2)$ & Reference & Reference \\
\hline With family & $140(24.1)$ & $442(75.9)$ & 0.13 & $0.15[0.14-1.73]$ \\
\hline Others $^{c}$ & $4(50)$ & $4(50)$ & 0.29 & $0.34[0.05-2.5]$ \\
\hline \multicolumn{5}{|l|}{ Current living condition } \\
\hline Dormitory & $125(21.6)$ & $454(78.4)$ & Reference & Reference \\
\hline In rented home & $21(75)$ & $7(25)$ & 0.5 & $0.38[0.02-6.15]$ \\
\hline Others $^{\mathrm{d}}$ & $2(16.7)$ & $10(83.3)$ & 0.4 & $3.56[0.18-71.5]$ \\
\hline \multicolumn{5}{|c|}{ Monthly pocket money (Ethiopian Birr) } \\
\hline$\leq 100$ & $3(11.5)$ & $23(88.5)$ & Reference & Reference \\
\hline $101-299$ & $15(15.6)$ & $81(84.4)$ & 0.95 & $0.95[0.18-4.85]$ \\
\hline $300-499$ & $35(21.2)$ & $130(78.8)$ & 0.95 & $0.97[0.33-2.85]$ \\
\hline 500-999 & $61(32.4)$ & $127(67.6)$ & 0.33 & $1.58[0.63-3.97]$ \\
\hline$\geq 1000$ & $27(30.3)$ & $62(69.7)$ & 0.4 & $1.4[0.61-3.37]$ \\
\hline \multicolumn{5}{|l|}{ Family's main source of income } \\
\hline Agriculture & $54(21.4)$ & $198(78.6)$ & Reference & Reference \\
\hline Trade & $48(33.8)$ & $94(66.2)$ & 0.61 & $1.8[0.16-21.75]$ \\
\hline
\end{tabular}


Table 2 Socio-demographic factors independently associated with current khat chewing among undergraduate students, Jimma University, Ethiopia, 2016 (Continued)

\begin{tabular}{lllll}
\hline Government job & $33(18.3)$ & $147(81.7)$ & 0.58 & $1.9[0.17-23.4]$ \\
NGO/private firm work & $10(31.25)$ & $22(68.75)$ & 0.73 & $1.53[0.13-17.45]$ \\
$\begin{array}{l}\text { Others } \\
\text { Family members currently chew khat }\end{array}$ & $3(23.1)$ & $10(76.9)$ & 0.37 & $3.4[0.24-48.3]$ \\
Yes & $105(63.6)$ & $60(36.4)$ & 0.001 & $15.6[8.3-29.5]$ \\
No & $43(9.5)$ & $411(90.5)$ & Reference & Reference \\
\hline
\end{tabular}

${ }^{a}$ Guraghe, Tigre, Wolayita, Sidama, Kaffa, Dawro, or Somali

${ }^{b}$ Protestant, Catholic, Hawariyat, or traditional

'Living with relatives or in own home with husband or wife

dLiving with relatives or family

e Ownbusiness

that a chronic khat chewer who stops chewing the leaf feels hot, especially in legs, and lethargic, has a desire to chew khat and has nightmares, mild depression, and a slight tremor [27]. This finding is comparable also to DSM-5 stimulant withdrawal diagnostic criterion "B," which specifies that dysphoric mood and two or more of the following physiological changes (fatigue, unpleasant dreams, insomnia or hypersomnia, increased appetite, and psychomotor retardation or agitation) should occur within a few hours to several days [32]. On the other hand, this finding was inconsistent with that of a study in Kenya, which found no signs of khat dependency or withdrawal symptoms [28]. In the present study, the mean duration of withdrawal symptoms was $23.3 \mathrm{~h}$. More than half $(55.4 \%)$ of the study participants who had withdrawal symptoms reported that it lasted for more than ten hours. A large proportion of those with withdrawal symptoms (66.3\%) reported that the symptoms caused impairment in social, occupational, or other important areas of their functioning. Just over half (52.5\%) of them reported they took different measures to get relief from the withdrawal symptoms: $34 \%$ use coca or coffee, $28.3 \%$ chew khat again, $20.75 \%$ sleep, $11.3 \%$ do sport or watch a movie, $3.7 \%$ take a shower, and $1.9 \%$ use candy for a long time. These findings are important indications of ways to improve health education for students and also show that students spend time and money to get relief from withdrawal symptoms.

We found that the following independent variables are significantly associated with khat chewing: male gender, attending a place of worship daily/2-3 times per week, current use of ganja/cannabis, current smoking cigarettes and having family members who are current khat chewers.

Table 3 Substance use other than khat and School related factors independently associated with current khat chewing among undergraduate students, Jimma University, 2016

\begin{tabular}{|c|c|c|c|c|}
\hline \multirow[t]{2}{*}{ Variables } & \multicolumn{2}{|c|}{ Current khat chewing } & \multirow[t]{2}{*}{$P$-value } & \multirow[t]{2}{*}{ AOR $(95 \% \mathrm{Cl})$} \\
\hline & Yes & No & & \\
\hline \multicolumn{5}{|l|}{ Cumulative grade point average (cGPA) } \\
\hline$<3.25$ (less than distinction level) & $67(28.2)$ & $171(71.8)$ & Reference & Reference \\
\hline$\geq 3.25$ (distinction level) & $50(21.8)$ & $179(78.2)$ & 0.38 & $0.82[0.53-1.27]$ \\
\hline \multicolumn{5}{|c|}{ Alcohol used at least once during the last 1 month } \\
\hline No & $82(19.2)$ & $345(80.8)$ & Reference & Reference \\
\hline Yes & $66(34.4)$ & $126(65.6)$ & 0.53 & $1.15[0.7-1.8]$ \\
\hline \multicolumn{5}{|c|}{ Smoking cigarettes at least once during the last 1 month } \\
\hline No & $89(18.5)$ & $392(81.5)$ & 0.001 & $0.45[0.3-0.7]$ \\
\hline Yes & $59(42.8)$ & $79(57.2)$ & Reference & Reference \\
\hline \multicolumn{5}{|c|}{ Ganja/cannabis used at least once during the last 1 month } \\
\hline No & $134(22.4)$ & $463(77.6)$ & Reference & Reference \\
\hline Yes & $14(63.6)$ & $8(36.4)$ & 0.004 & $4.17[1.6-11.2]$ \\
\hline \multicolumn{5}{|c|}{ Shisha used at least once during the last 1 month } \\
\hline No & $129(24)$ & $408(76)$ & Reference & Reference \\
\hline Yes & $19(23.2)$ & $63(76.8)$ & 0.9 & $1.02[0.51-2.06]$ \\
\hline
\end{tabular}


In our study, male students had 2.3 higher odds of chewing khat than female students [AOR 2.3, 95\% CI: $1.16,4.6]$. This finding is supported by similar findings from studies among Ethiopian students at Axum University and Haramaya University and Ethiopian college students in Bahir Dar town [29, 34, 38]. The difference between males and females could be due to cultural restrictions, because in Ethiopia females are less exposed to khat chewing than males [38].

Irrespective of their religion, students who were attending a place of worship daily or 2-3 times per week were $90 \%$ less likely to chew khat than students who never attended a place of worship during the last month (AOR 0.1, 95\% CI: 0.03, 0.29). This result is in line with that of a previous study at Gondar University [35]. A possible explanation for this finding could be that substance use is not supported by religious teaching [15].

Students those who have family members currently chewing khat had 15.6 times higher odds of chewing khat than those who have no family members currently chewing khat (AOR 15.6, 95\% CI: 8.3, 29.5). This finding is in agreement with the findings of previous studies in college students in Bahir Dar Town [38] and students at Axum University in Ethiopia [29] and Jazan University in Saudi Arabia [33]. Khat chewing could be associated with chewing among family members for a number of reasons: the family might have a common protective factor that serves all family members, such as family policy, religion, etc.; and khat chewing might be less socially acceptable in families that do not chew khat.

Students who had used cannabis at least once during the last month had more than four times higher odds of chewing khat than those who did not use it during the last month (AOR 4.17, 95\% CI: 1.6, 11.2). This finding shows that poly-substance use behavior can be found among students with a khat chewing habit [15].

Students those who had not smoked cigarettes during the last month were 55\% less likely to chew khat than those who had smoked cigarettes at least once during the last month (AOR 0.45, 95\% CI: 0.3, 0.7). This finding is in agreement with study conducted among university students in Northwest Ethiopia [35].

This study has some limitations. First, the crosssectional study design does not determine a cause and effect relationship (the chicken and egg dilemma). Second, self-administered data might increase the social desirability bias and non response rate, which can underestimate the prevalence of khat chewing. Despite these limitations, the study has several strengths, including the following: (I) the response rate was relatively high and the sample size was relatively large; (II) the sampling procedure and analysis methods were appropriate for the study; (III) the study investigated withdrawal symptoms for the first time in Ethiopia.

\section{Conclusions}

To conclude, this study found that large numbers of university students chew khat. The study gave new ideas regarding khat withdrawal symptoms in Ethiopia. The most frequently reported withdrawal symptoms were feeling depressed, craving, and feeling fatigued. Factors those were significantly associated with khat chewing were male gender, attending a place of worship daily/23 times per week, currently using ganja/cannabis, current smoking cigarettes and having family members who chew khat. The study findings serve as a critical role of providing information to form rational foundation for public health policy, prevention and planning to bring change in contributing factors for Khat chewing. The finding will be serving as base line information for further study.

\section{Abbreviations}

AOR: Adjusted odds ratio; CGPA: Cumulative grade point average;

COR: Crude Odds Ratio; ETB: Ethiopian Birr; IOT: Institute of Technology; NGO: Non Government Organization; SPSS: Statistical Package for Social Science; WHO: World Health Organization

\section{Acknowledgements}

The study was funded by the Jimma University College of Health Sciences. The authors would like to gratefully acknowledge the undergraduate students of the main campus who enthusiastically participated in this study for their time and for sharing their experiences with us. We also thank Jacquie Klesing, Board-certified Editor in the Life Sciences (ELS), for language editing assistance with the manuscript.

\section{Funding}

Not applicable.

\section{Availability of data and materials}

All data and materials related to study can be obtained through contacting the corresponding author at tilahunabdeta@gmail.com.

\section{Authors' contributions}

TA contributed to the conceiving the original idea, designing the research, conduct and analysis of the research and in the manuscript preparation and in the review of the manuscript. DT contributed to the design, conduct and analysis of the research and in the manuscript preparation. KA contributed to the design, conduct and analysis of the research and in the manuscript preparation. MA contributed to the conceiving the original idea, designing the research, conduct and analysis of the research and in the manuscript preparation. All authors read and approved the final version of the manuscript.

\section{Competing interests}

The authors declare that they have no competing interests.

\section{Consent for publication}

Not applicable as the manuscript does not contain individual-level data.

\section{Ethics approval and consent to participate}

The study was conducted after approval obtained from the ethical review board of College of Health Sciences, Jimma University. Written informed consent was obtained from the study participants after providing clear explanation about the objective of the study immediately before distributing the questionnaire. The collected data were kept confidential. Participants' right to refuse and the chance to ask any thing about the study was strictly respected. The names of the participants were not written.

\section{Publisher's Note}

Springer Nature remains neutral with regard to jurisdictional claims in published maps and institutional affiliations. 


\section{Author details}

'Department of Psychiatry, School of Nursing and Midwifery, College of Medical and Health Sciences, Haramaya University, Harar, Ethiopia. ${ }^{2}$ Department of Psychiatry, Medical College, Adama, Ethiopia. ${ }^{3}$ Department of Psychiatry and Psychotherapy, Ludwig-Maximilians-University, Munich, Germany. ${ }^{4}$ Institute of Psychiatric Phenomics and Genomics, Munich, Germany. ${ }^{5}$ Center for International Health, Ludwig-Maximilians-University, Munich, Germany. ${ }^{6}$ Department of Psychiatry, College of Health Sciences, Jimma University, Jimma, Ethiopia.

Received: 29 October 2016 Accepted: 24 March 2017 Published online: 17 April 2017

\section{References}

1. Berhanu M, Aregash E, Alyi M. Socio-Economic Impact of Khat in Mana District, Jimma Zone, South Western Ethiopia. Discourse J Agric Food Sci. 2014;2(2):21-32.

2. Reda AA, Moges A, Biadgilign S, Wondmagegn BY. Prevalence and determinants of Khat (Catha-edulis) Chewing among High School Students in Eastern Ethiopia, A Cross-Sectional Study. PLoS ONE. 2012;7(3):1-2.

3. Nencinp I, Rassmsci G, Botana A, Asseyar F. Khat chewing spread to the Somali community in Rome. Drug Alcohol Depend. 1988;23(4):255-8.

4. Aseffa M. Socio-economic aspects of khat in the Harrarghe administrative region. Antananarivo, Madagascar: Ethiopia. Proceedings of the International Conference on Khat; 1983.

5. Ezekiel G. Khat in the Horn of Africa: Historical perspectives and current trends. J Ethnopharmacol. 2010;132(3):607-114.

6. Nasir TW. Chemistry, Pharmacology, and Toxicology of Khat (Catha edulisforsk) a Review. Addict Health. 2011;3(3-4):137-49.

7. Geisshusler S, Brenneisen R. The content of psychoactive phenylpropyl and phenylpentenylkhatamines in Catha edulis Forsk of different origin. J Ethnopharmacol. 1987;19(3):269-77.

8. Feyissa AM, Kelly JP. A review of the neuropharmocological properties of khat. Prog Neuro-Psychopharmacol Biol Psychiatry. 2008;32(5):1147-66.

9. Hussain MAA. Health and Soci-economic Hazard associated with Khat consumption. J Fam Community Med. 2013;15(1):3-11.

10. Wakgari D, Aklilu A. Substance use and its predictors among undergraduate medical students of Addis Ababa University in Ethiopia. BMC Public Health. 2011;11(660): doi: 10.1186/471-2458-11-660.

11. Kalix P. Khat: scientific knowledge and policy issues. Br J Addict. 1987:82:47-53.

12. Elmai. Khat consumption and problems in Somalia, Proceedings of the International Conference on Khat, Antananarivo, Madagascar; 1983.

13. Morghemm M, Rufatm I. Cultivation and chewing of khat in the Yemen Arab Republic. Proceedings of the International Conference on Khat, Antananarivo, Madagascar; 1983.

14. Getajiu A, Krikoriaand N. The economic and social importance of khat and suggested research and services, Proceedings of the International Conference on Khat, Antananarivo, Madagascar; 1983.

15. Sinshaw A, Kassa H, Messele A. Prevalence and Associated Factors of Khat Chewing Among Atse Fasil Campus Students, University of Gondar, North West Ethiopia. J Psychol Clin Psychiatry. 2013;1(6):00040.

16. Wilder P, Mathys K, Brenneisen R, Kalix P, Fisch HU. Pharmacodynamics and pharmacokinetics of khat: a controlled study. Clin Pharmacol Ther. 1994;5595:556-62.

17. Heymann T, Bhupulan A. Khat chewing delays gastric emptying of a semisolid meal. Aliment Pharmacol Ther. 1995;9(1):81-3.

18. Al-Motarreb A, Baker K, Broadley KJ. Pattern of chat abuse and its adverse effect. Adv Psychiatr Treat. 2002;6:403-13.

19. Glenice C, Hagen R. Adverse effect of khat. Adv Psychiatr Treat. 2003;9:456-63

20. Van Heerden MS, Grimsrud AT, Seedat S, Myer L. Patterns of substance use in South Africa: Results from the South African Stress and Health study. Med J. 2009;99(5 Pt 2):358-66.

21. Al-Sanosy RM. Pattern of khat abuse and academic performance Among Secondary School and College students in Jazan region, kingdom of Saudi Arabia (KSA). Fam Community Med. 2009;16(3):89-95.

22. Judy H, Antonio G, Douglas C. Mental Health and Substance Use Disorders among Foster Youth Transitioning to Adulthood. Child Youth Serve Rev. 2013;35(1):194-203.
23. Anne K, Myhrene S. Mental Distress and Psychotropic Drug Use among Young People. Karlstad Univ Stud. 2014;2(3):146-8.

24. Michael O, Frank N, Maggie S, Thomas E, Claudia C, Birke L, et al. Khat use as risk factor for psychotic disorders: A cross-sectional and case-control study in Somalia. BMC Med. 2005;3:5. doi:10.1186/1741-7015-3-5.

25. Ali WM, Zubaid M, Al-Motarreb A, Singh R, Al-Shereiqi SZ, Shehab A, et al. Association of Khat Chewing With Increased Risk of Stroke and Death in Patients Presenting With Acute Coronary Syndrome. Mayo Clin Proc. 2010;85(11):974-80.

26. WHO. Assessment of Khat (Catha edulisforsk). Geneva: WHO; 2006. 66(8):45-46

27. Al-Motarreb A, Baker K, Broadley KJ. Khat: pharmacological and medical aspects and its social use in Yemen. Phytother Res. 2002;16:403-13.

28. Othieno CJ, Kathuku DM, Ndetei DM. Substance abuse in outpatients attending rural and urban health centres in Kenya. East Afr Med J. 2000;77:592-5.

29. Gebreslassie M, Feleke A, Melese T. Psychoactive substances use and associated factors among Axum university students, Axum Town, North Ethiopia. BMC Public Health. 2013;13:693.

30. Awoke L, Behailu T, Nigussie D, Yared R. Prevalence of Catha edulis (Khat) Chewing and its associated factors among Ataye Secondary School Students, in Northern Shoa, Ethiopia. J Addict. 2014;1(4):225-33.

31. Central Statistical Authority. Statistical Abstract of Ethiopia. Addis Ababa: CSA; 2007.

32. Benjamin James Sadock, Virginia Alcott Sadock, Pedro Ruiz. New York: Kaplan N sadock's Synopsis of Psychiatry-BS-Clinical Psychiatry. 11E; 2015. p. 583-584.

33. Rashad M, Mohamed SA, Abdelrahim M. Khat Chewing Habit among higher education Students of Jazan Region, Saudi Arabia. PLoS ONE. 2013;8(6): e65504. doi:10.1371/journal.pone.0065504.

34. Tesfaye G, Derese A, Hambisa MT. Substance Use and Associated Factors among Haramaya University Students, Harar, Ethiopia: A Cross-Sectional Study. J Addict. 2014;1 (2):3-4.

35. Dachew BA, Bifftu BB, Tiruneh BT. Khat use and its determinants among university students in northwest Ethiopia: a multivariable analysis. Int J Med Sci Public Health. 2015;4:319-23.

36. Kebede Y. Cigarette smoking and khat chewing among college students in North West Ethiopia. Ethiop J Health Dev. 2002;16(1):9-17.

37. Lemessa D. Khat (Catha edulis): Botany, distribution, cultivation, usage and economics in Ethiopia. Addis Ababa: UN-EOE. 2001;1:4-5.

38. Mulugeta Y. Khat Chewing and its associated Factors among College Students in Bahir Dar Town, Ethiopia. Sci J Public Health. 2013;1(5):209-14.

\section{Submit your next manuscript to BioMed Central and we will help you at every step:}

- We accept pre-submission inquiries

- Our selector tool helps you to find the most relevant journal

- We provide round the clock customer support

- Convenient online submission

- Thorough peer review

- Inclusion in PubMed and all major indexing services

- Maximum visibility for your research

Submit your manuscript at www.biomedcentral.com/submit
Biomed Central 